\title{
Los intérpretes de Napoleón: guerra total y batalla decisiva
}

\section{The Interpreters of Napoleon: Total War and Decisive Battle}

\section{José Pardo de Santayana ${ }^{1}$ \\ Coordinador de Investigación del Instituto Español de Estudios Estratégicos (España)}

Recibido: 21-04-20

Aprobado: 07-06-20

\section{Resumen}

Tras las guerras napoleónicas aparecieron un conjunto de pensadores, los más destacados fueron Clausewitz y Jomini que permitieron que la estrategia naciera como ciencia. Napoleón asombró al mundo por su capacidad para, por medio de rápidas campañas ofensivas, imponerse a su enemigo en una batalla decisiva dirigida contra el grueso de las fuerzas opuestas. Acabado aquel periodo de continuas contiendas militares las condiciones para el ejercicio de la actividad militar cambiaron radicalmente. Frente a la capacidad destructora de las armas, la ofensiva perdió impulso y se imponían enormes esfuerzos organizativos para poner en pie unos ejércitos que habían crecido en volumen. Helmut von Moltke entendió la naturaleza de dicha transformación y fue capaz de vencer de nuevo por medio de unas batallas decisivas que parecían reafirmar los principios napoleónicos. Esta circunstancia impidió comprender la profundidad de la

\footnotetext{
${ }^{1}$ (jparygo@mde.es) El coronel José Pardo de Santayana es coordinador de investigación del Instituto Español de Estudios Estratégicos, miembro de número de la Fundación de la Academia de las Ciencias y las Artes Militares, miembro colaborador de la Academia de la Historia de Cuba y presidente de la Fundación Tomás Moro.

Ha sido profesor de Estrategia e Historia Militar de las escuelas de Estado Mayor y de Guerra del Ejército. Es autor del libro Francisco de Longa, de guerrillero a general en la Guerra de la Independencia y coautor de los libros El conflicto de Afganistán y El conflicto de los Grandes lagos.

En la actualidad está traduciendo del francés al español la obra en XIII volúmenes "Contribución a la historia de la Guerra de la Independencia de la Península Ibérica contra Napoleón I" de Jean Sarramon.
} 
trasformación que el fenómeno bélico estaba conociendo y llevó al estancamiento y la carnicería de la Primera Guerra Mundial.

Palabras-clave: Estrategia, Napoleón, Clausewitz, Moltke, guerra total, batalla decisiva.

\begin{abstract}
After the Napoleonic Wars, a set of thinkers appeared, the most prominent of which were Clausewitz and Jomini, who allowed the strategy to be born as science. Napoleon astonished the world by his ability to, through swift offensive campaigns, prevail against his enemy in a decisive battle directed against the bulk of the opposing forces. After that period of continuous military strife, the conditions for the exercise of military activity changed radically. In the face of the weapons' destructive capacity, the offensive lost momentum and huge organizational efforts were required to set up armies that had grown. Helmut von Moltke understood the nature of this transformation and was able to win again through decisive battles that seemed to reaffirm Napoleonic principles. This prevented understanding of the depth of the transformation that the war phenomenon was experiencing and led to the stagnation and carnage of World War I.
\end{abstract}

Key-words: Strategy, Napoleon, Clausewitz, Moltke, Total War, Decisive Battle.

\title{
Introducción
}

Todo el mundo ha oído hablar de Clausewitz, Napoleón es uno de los personajes más conocidos de la historia y Helmut von Moltke, aunque casi olvidado, ha sido probablemente el militar con mayor influencia en el desarrollo de la guerra moderna. Desde el siglo XIX, la estrategia como materia de estudio y reflexión ha conocido un desarrollo asombroso. Nos podríamos preguntar ¿a qué se debe todo esto? La respuesta a esta cuestión es uno de los capítulos más interesantes del estudio del fenómeno bélico.

Existe además un cierto romanticismo y hasta una marcada fascinación en torno a las guerras napoleónicas, las últimas guerras donde el guerrero heroico y el líder militar carismático encontraron un lugar de privilegio en la batalla. Apagado el tronar de los cañones empezó un nuevo periodo histórico donde el poder destructivo de las armas dio un giro de 180 grados al modo de hacer la guerra: una actividad presidida a partir de entonces por un modelo organizativo de inspiración industrial. 
No obstante, entre la era napoleónica y la de las guerras mundiales pasó un siglo de paz interrumpido únicamente por un breve periodo de guerras limitadas en las que nació la estrategia como ciencia, pero donde el fenómeno bélico no llegó a volver a experimentarse en su dimensión totalizante. Los principios deducidos de aquel cuarto de siglo de continuo guerrear que siguió a la Revolución Francesa llegaron casi intactos al alborear del siglo XX.

El nacionalismo exacerbado, buenas dosis de militarismo y la rivalidad entre las potencias de aquellos años llevaron a las naciones europeas al borde del abismo. El hombre racional terminó perdiendo el control del instrumento militar y la guerra, como le pasó al aprendiz de brujo, adquirió una dinámica propia. La Primera Guerra Mundial supuso el fracaso más rotundo del arte militar y una tragedia de dimensiones bíblicas.

En un diálogo profundo con dicha hecatombe, la Segunda Guerra Mundial impulsó la acción bélica hasta su apogeo definitivo en un frenesí de barbarie y capacidad de superación humana. El arma nuclear, que hace su aparición al final de la segunda gran contienda, se ha ocupado de preservarlo. El enfrentamiento armado nunca volverá a recobrar aquel perfil de guerra total, esta podría desencadenar el empleo del arma nuclear, lo cual, a su vez, llevaría al apocalipsis.

Este capítulo pretende presentar la evolución del pensamiento estratégico desde el final de las guerras napoleónicas hasta el inicio de la Primera Guerra Mundial. El centro de gravedad descansa en los principales pensadores y su interacción con la experiencia de la guerra para intentar comprender cómo una actividad intelectual tan fecunda pudo tener como resultado un fracaso tan atronador.

\section{La actividad militar alcanza la madurez}

Durante el siglo XVIII, se habían dado importantes avances en el arte militar y en las condiciones para el ejercicio de la actividad bélica: mejoras de las carreteras, generalización de la confección de planos más precisos, extensión de la educación que permitió un mayor empleo de ordenes escritas, mayor alcance, precisión y movilidad de la artillería, normalización de sus calibres, concienzuda formación de los oficiales, espíritu ilustrado, entre otros. Todo ello facilitó un importante progreso del modo de emplear la fuerza que llevaría a Guibert a decir: "Dejemos que aparezca, tiene que aparecer un gran genio. Se pondrá a cabeza de la máquina y le dará el impulso necesario"².

Francia, que había liderado a finales de dicho siglo la reflexión para el desarrollo del modo de hacer la guerra desde concepciones racionalistas,

${ }^{2}$ Antonio Martínez Teixidó, Enciclopedia del Arte Militar, Barcelona, Editorial Planeta, 2001, p. 183. 
fundió el legado militar del antiguo régimen con dos importantes aportaciones de la Revolución Francesa: la pasión del emergente nacionalismo y la movilización en masa de Carnot. El gran ejército de ciudadanos en armas, identificado con la causa por la que se luchaba, sustituía al pequeño ejército profesional cohesionado por una férrea disciplina. La columna, mucho más maniobrera, se abría camino frente a la rígida línea. Con la división en cuerpos de ejército de la nueva orgánica imperial, la Grande Armée pudo maniobrar por rutas separadas para concentrarse en el lugar designado o acudir al ruido del cañón. Liberadas de la tiranía de la logística, las fuerzas napoleónicas, que se suministraban sobre el terreno, ganaron movilidad y profundidad en sus maniobras. La formidable maquinaria militar en manos del emperador de los franceses entraba en acción antes de que sus oponentes pudieran reaccionar e incluso antes de que siquiera entendieran lo que estaba ocurriendo. El gran corso llegó a cimentar su imperio sobre los mitos de invencibilidad y de liberador de los pueblos.

Ocultando sus intenciones con la fuerza extendida en amplio despliegue y a cubierto de una barrera natural, Napoleón lanzaba una operación rápida que buscaba el envolvimiento del enemigo o la ruptura de su frente. Una vez sorprendido su enemigo y sin capacidad para escapar de la trampa, el general Bonaparte forzaba una batalla decisiva contra el grueso de la fuerza oponente. Con la capital de su víctima a su merced, el emperador dictaba las condiciones de paz y, en unos pocos meses, había conseguido cambiar el mapa de Europa. Tanto la guerra como la batalla se habían vuelto resolutivas, poniendo toda la energía de la sociedad al servicio de la causa bélica.

Con el tiempo, los enemigos del intempestivo Bonaparte aprendieron un nuevo estilo de hacer la guerra, transformaron sus ejércitos según el patrón francés y lo derrotaron. En el Congreso de Viena restauraron el antiguo régimen. No obstante, las fuerzas que la revolución política y social había liberado, combinadas con las capacidades materiales que la Revolución Industrial había propiciado, transformaron para siempre las dinámicas militares.

El periodo de guerras tan intenso y prolongado que se extendió desde la Revolución Francesa (1789) hasta el ocaso de Napoleón (1815) permitió un análisis sistemático del fenómeno bélico y dio lugar a la aparición de una serie de teóricos de la guerra que hicieron nacer el pensamiento estratégico como ciencia. Las dos figuras señeras fueron Jomini y Clausewitz, ambos fueron testigos y participaron de forma directa en aquella formidable aventura militar. 


\section{Jomini}

Antoine-Henri Jomini nació en Suiza en 1779. Con 19 años abandonó lo que podría haber sido una brillante carrera comercial para dedicar los siguientes 70 años primero al ejercicio y después al estudio de las operaciones militares. Con el fin de dar al estudio de la guerra el carácter de "científico", redujo su estudio a la "estrategia operativa". Su concepción general sobre la problemática del fenómeno bélico, abstrayéndole de su contexto político y social, dando énfasis al proceso de la toma de decisiones y a los resultados operativos, convirtió la guerra en un enorme juego de ajedrez ${ }^{3}$, lo que se ha dado a conocer como el álgebra de la acción.

Su sistematización de la lógica que pone en relación cantidad de fuerzas, recursos disponibles, teatro militar, posiciones relativas y liderazgo militar permitió poner las bases para el desarrollo de los estudios estratégicos.

Su obra más importante es el Compendio del arte de la guerra (1838). Su trascendencia radica en que proporcionó una nueva nomenclatura estratégica que, unido a su principio fundamental del arte de la guerra: escoger y coordinar la maniobra que conduzca al punto decisivo, han constituido el fundamento en las concepciones estratégicas del siglo XIX ${ }^{4}$. Junto con él aparecieron otros pensadores como el duque de Ragusa y Wilhelm von Willissen que siguieron una línea de pensamiento similar.

El modo napoleónico de abordar las operaciones quedó plasmado en todos los tratados de la época, lo que se tradujo en la superioridad de la ofensiva y en la estrategia de la acción directa que busca la destrucción del grueso de la fuerza enemiga por medio de una operación rápida culminada por una gran batalla decisiva. El alma del ejército residía en el liderazgo del general en jefe que debía tanto movilizar las energías necesarias como concebir las operaciones.

\section{Clausewitz}

Carl von Clausewitz nació en el ducado de Magdeburgo (reino de Prusia) en 1780. Aunque contemporáneo de Jomini, tardó más en darse a conocer. Se alistó en el Ejército prusiano a la edad de 12 años. Tuvo una activa participación en las guerras de aquella época. Fue colaborador cercano de los grandes reformadores militares prusianos von Scharnhorst y von Gneisenau. Ambos, de procedencia hanoveriana y austriaca,

\footnotetext{
3 John Shy, "Jomini", Creadores de la estrategia moderna: desde Maquiavelo a la era nuclear, obra coordinada por Peter Paret, Madrid, Ministerio de Defensa, 1991, pp. 157-158.

4 Antonio Martínez Teixidó, op. cit., p. 199.
} 
son considerados los mayores genios militares de la época después de Napoleón ${ }^{5}$.

Clausewitz gozó de la amistad y tutela de ambos reformadores y de una amplia formación intelectual, en gran parte autodidacta. Desde 1818, cuando fue ascendido a mayor general, hasta 1830 fue director de la academia militar prusiana donde estudió Helmut von Moltke, que fue quien le daría a conocer varias décadas después.

Tras su muerte, su mujer publicó, en 1832, los manuscritos inacabados de su obra más importante. Von Kriege ("De la guerra") se convertiría en un tratado de referencia obligada. A lo largo de ocho volúmenes analiza el fenómeno de la guerra, desde su planteamiento y motivaciones hasta su ejecución, abarcando los aspectos logísticos, tácticos, operativos y estratégicos. Pero, por encima de todo ello, lo que le hace tan relevante es su enfoque filosófico. El idear esquemas estratégicos y nuevas tácticas le interesaban mucho menos que identificar los elementos permanentes de la guerra y llegar a comprender los mecanismos que rigen su funcionamiento ${ }^{6}$.

Para Clausewitz, la guerra no es un acto autónomo o aislado, sino esencialmente un acto de carácter político, de donde deriva su racionalidad. En su concepción, entran en juego además los otros dos elementos de la guerra: violencia y pasión y el juego de incertidumbre, oportunidad y probabilidad. La pasión interesa especialmente al pueblo; el juego, oportunidad y probabilidad, al comandante en jefe y a su ejército, y la razón política, solamente al gobierno, formando lo que designó como una "trinidad" inseparable?

La lógica de la acción, donde el que más se empeña lleva la ventaja, impulsa el fenómeno bélico hacia la guerra total. Esta tendencia puede ser moderada por razones políticas, pensaba Clausewitz, pero no por ello dejaba de ser un elemento vertebrador de la dinámica guerrera.

El pensamiento estratégico del militar prusiano sigue vigente para comprender el fenómeno bélico en toda su complejidad.

\section{Trasmisión de los principios napoleónicos}

Después de silenciarse los caños de las batallas napoleónicas devino un gran periodo de paz, lo que produjo un estancamiento del desarrollo de la teoría militar la cual perdió contacto con la realidad bélica en profunda

\footnotetext{
5 Hajo Holborn, "Moltke and Schlieffen: The Prussian-German School", Makers of Modern Strategy, obra editada por Edward Mead earle, Princeton University Press, 1971, p. 173.

6 Peter Paret, "Clausewitz", Creadores de la estrategia moderna: desde Maquiavelo a la era nuclear, obra coordinada por Peter Paret, Madrid, Ministerio de Defensa, 1991, p. 200.

7 Ibidem, p. 2012.
} 
transformación ${ }^{8}$. La Revolución Industrial empezó a cambiar la capacidad del hombre para producir, para trasladarse y para modificar su entorno. La máquina sustituyó al esfuerzo de hombres y animales. Todas las dimensiones de la actividad humana se expandieron. La producción en masa de las fábricas encontró su analogía en la capacidad de destrucción en masa de las armas y en la capacidad para movilizar mayores cantidades de recursos humanos y materiales para la actividad militar.

Los padres de la estrategia como ciencia, en vez de dotar a las mentes de recursos intelectuales para entender la revolución militar que estaba ocurriendo, ejercieron paradójicamente el efecto contrario. Los expertos militares a los que formaron estaban preparados para combatir una guerra del pasado con unos principios en gran parte superados por los avances tecnológicos y sociales. El pensamiento clausewitziano, gracias a su dimensión más filosófica, estaba menos anclado a las circunstancias de un tiempo determinado, pero todavía no se había dado a conocer.

Cuando los ejércitos se volvieron a enfrentar a mediados del siglo XIX, la guerra presentó un perfil mucho menos heroico, más desordenado y con mayores índices de mortalidad. Parecía que sin la experiencia de la guerra no hubieran podido nacer verdaderos generales. El romanticismo de la guerra se había esfumado definitivamente. En dicho contexto de confusión, hubo un general prusiano que se adelantó a los demás y entendió que la guerra había adquirido una nueva dimensión y que únicamente podía ser abordada con un cambio de naturaleza conceptual y organizativa. ¡Había nacido el nuevo modelo militar de la era industrial!

\section{Moltke}

Helmut von Moltke nació en 1800 en el ducado de Holstein (entonces feudo del rey de Dinamarca) en el seno de una familia prusiana. Con 11 años ingresó en la escuela de cadetes de Copenhague. 11 años después pasó al Ejército prusiano donde se convirtió en alumno aventajado de la Escuela General de Guerra de Berlín. Su inteligencia y discreción, así como su exactitud y pulcritud en el servicio, le abrieron las puertas de la corte.

Tuvo ocasión de observar en persona la evolución que estaba sufriendo la guerra como consecuencia tanto del crecimiento de los ejércitos como de los efectos cada más destructivos de las nuevas armas. Dedicó mucho tiempo al estudio, a escribir sobre historia militar y a la confección de mapas, pero hasta la última etapa de su vida militar no tuvo experiencia ni en combate ni en el mando de tropas.

\footnotetext{
${ }^{8}$ Stefan T. Possony y Etienne Mantoux, "The French School”, Makers of Modern Strategy, obra editada por Edward Mead Earle, Princeton University Press, 1971, p. 206.
}

Araucaria. Revista Iberoamericana de Filosofí, Política, Humanidades y Relaciones Internacionales, año $22, \mathrm{n}^{\circ} 44$. Segundo semestre de 2020. Pp. 387-398. ISSN 1575-6823 e-ISSN 2340-2199 https://dx.doi.org/10.12795/araucaria.2020.i44.18 
Fue ayudante del príncipe Federico Guillermo y, en 1857, el rey Guillermo I le nombró jefe del Estado Mayor del Ejército prusiano. Dirigió las fuerzas prusianas en las guerras de los Ducados de 1864, austro-prusiana de 1866 y franco-prusiana de 1870-71.

Los éxitos obtenidos en dichas campañas asombraron al mundo. Cuando fue preguntado sobre las principales obras que le habían servido de inspiración citó, entre otras, Vom Kriege de Clausewitz, lo que sacó a este último del anonimato. Los principales ejércitos del mundo empezaron a estudiar las campañas de Moltke, aunque sacaron de ellas conclusiones en parte equivocadas.

Moltke nunca pretendió establecer una teoría sobre la guerra. Su enfoque, en consonancia con el pensamiento filosófico dominante, era positivista y no consideraba que hubiera principios que determinaran el arte de la guerra. Se centraba en hacer planes militares para distintas campañas potenciales y pensaba que cada circunstancia dictaba un modelo de respuestas distinto, manteniendo una gran flexibilidad y una destacada apertura de miras ${ }^{9}$.

El punto de partida de su reflexión era la observación de que el volumen de los ejércitos ya no permitía reunirlos antes de dar la batalla, dado que esto los inmovilizaría. Había pues que dividir la fuerza en distintos ejércitos que habían de marchar por separado para converger sobre el grueso del enemigo en el mismo campo de batalla. El general en jefe, buscando siempre mantener la iniciativa, debía conducir dichos ejércitos indicando la dirección de su avance, de ahí el término directiva. El ferrocarril y el telégrafo jugaban un papel clave para el despliegue, abastecimiento y sistema de comunicación de los ejércitos.

La principal diferencia con el modo de actuar de los otros líderes militares de su tiempo es que preparaba la ejecución del plan hasta el más mínimo detalle de modo que, al iniciarse la guerra, únicamente tenían que distribuirse las órdenes ya elaboradas y esperar hasta el primer encuentro. Esto dio lugar a un formidable sistema de movilización más ordenado y rápido que lo conocido hasta entonces. Para llevar a cabo este nuevo modo de hacer la guerra, el general prusiano conformó el Estado Mayor a su medida: capaz de preparar minuciosos planes y ejecutar la voluntad del jefe durante las operaciones.

Una de sus pocas máximas era que no hay plan que sobreviva al primer choque con el enemigo, por lo que a partir de dicho momento el general en jefe tenía que guiar los ejércitos por directivas para buscar una resolución favorable. Dada la fortaleza que la defensa de una línea estaba adquiriendo, la forma preferida de abordar una formación enemiga era el envolvimiento, lo que daba la ventaja al que era capaz de reforzar más rápidamente la fuerza empeñada. Para Moltke, la actitud ofensiva o defensiva vendría impuesta por las circunstancias, en principio, no era partidario de una u otra.

\footnotetext{
${ }^{9}$ Hajo Holborn, op. cit, p. 185.
} 
La movilidad de los ejércitos que marchaban por separado, la agilidad del sistema de directivas y la ordenada y rápida movilización permitieron a Moltke superar a sus enemigos en poco tiempo por medio de grandes batallas envolventes que resultaron decisivas. La victoria se producía antes de que sus oponentes hubieran tenido tiempo de tomar el control de la situación. Todo hacía pensar que se trataba de una réplica de la forma napoleónica de hacer la guerra.

La experiencia de la Guerra de Secesión norteamericana (1861-1865), donde hubo más simetría en el modo de emplear la fuerza, mostró lo contrario: tendencia al estancamiento, poder de las fortificaciones, fracaso del ataque frontal, importancia del poder industrial, entre otras cuestiones. Las potencias europeas despreciaron las lecciones aprendidas de dicha guerra. Con sus campañas rápidas y sus batallas decisivas, Moltke había creado un espejismo, posible únicamente porque había entendido cómo estaba cambiando la guerra y los demás no. Cuando esa ventaja desapareció, porque los demás ejércitos adoptaron el modelo de movilización prusiano, reaparecería la tendencia al estancamiento de las operaciones militares. No obstante, hubo que esperar varias décadas porque, tras la guerra franco-prusiana, la paz volvió a reinar en Europa.

\section{El camino hacia las trincheras, el barro y el fracaso del arte de la guerra}

Después de los repetidos éxitos del general prusiano, los ejércitos europeos adoptaron lo que se interpretó como el modelo prusiano, una reencarnación de los principios napoleónicos adaptados a las nuevas circunstancias del progreso ${ }^{10}$, creyendo que iban a conseguir también los resultados obtenidos por Moltke y Bonaparte: una rápida campaña concluida por una gran batalla decisiva. Para salir victorioso, había que poner todo el énfasis en el proceso de movilización. Quien movilizara antes más tropas ganaría la guerra. Como Moltke había vencido también en todas sus campañas por medio de operaciones ofensivas, la actitud ofensiva se reafirmó como la forma superior de hacer la guerra.

Los Estados Mayores empezaron a preparar planes para lanzar a la batalla grandes masas de tropas, las necesidades de dichos planes condicionaron la estrategia, la diplomacia se acomodó a las exigencias militares, la rigidez de los mecanismos de movilización y la falta de planes alternativos dejó sin margen de maniobra a los gobiernos ${ }^{11}$.

${ }^{10}$ Gunther E. Rothenberg, "Moltke, Schlieffen y la Doctrina del envolvimineto Estratégico", Creadores de la estrategia moderna: desde Maquiavelo a la era nuclear, obra coordinada por Peter Paret, Madrid, Ministerio de Defensa, 1991, p. 313.

11 The Great War, editado por Thomas E. Griess, the Wets Point Military History Series, New 
La expansión colonial y las categorías neodarwinistas dieron al enfrentamiento geopolítico una mística supremacista y belicista. El sistema de alianzas, previsto para evitar la guerra, vinculó la suerte de unas naciones y otras. Durante los años de la "paz armada", todas las potencias se empeñaron a fondo por mejorar sus capacidades militares. El militarismo y el extremo nacionalismo empujaron a las naciones hasta el umbral de la guerra.

Un acontecimiento tangencial en Sarajevo encendió la mecha. Pensando que la guerra duraría poco y que se resolvería por medio de una gran batalla, los gobiernos y los Estados Mayores se vieron atenazados por la prisa y la ansiedad. La falta de conciencia de las dimensiones que la contienda iba a alcanzar impidió que se crearan mecanismos de freno suficientemente sólidos. El 30 de julio de 1814, el zar Nicolás II dio la orden de movilización general, cinco días después la Gran Guerra ya había arrastrado hacia sí a las principales potencias. Los jóvenes acudieron prestos a los banderines de enganche. ¡No querían llegar tarde a la batalla decisiva! La gran tragedia se inició sin que Europa supiera que se dirigía a su autoinmolación.

La Primera Guerra Mundial representa el fracaso del pensamiento estratégico. ¡Qué paradoja que haya sido el resultado de un esfuerzo intelectual tan prodigioso!

Los éxitos militares tienden a ser imitados en las siguientes guerras. Recientemente, hemos visto cómo los EE. UU. se han dejado arrastrar por el espejismo de la victoria en la Revolución de Asuntos Militares. La experiencia enseña que cada guerra es distinta y debe ser combatida con nuevos principios que se adapten a las condiciones estratégicas específicas. Además, las pasiones y los laberintos que las guerras propician producen fenómenos muchas veces contraproducentes e imprevisibles. El pensamiento estratégico debe ser crítico, incisivo y prudente, siempre necesitado de un buena dosis de sabiduría.

\section{Conclusión}

Cuando la reflexión militar llevada a cabo en el siglo XVIII -especialmente por Francia-, incorporada a las profundas transformaciones que produjo la Revolución Francesa que impulsó el enfrentamiento militar hasta la guerra total, cayó en manos además de un genio como Napoleón, se produjo un momento prolongado de apogeo del arte militar. Este terreno fértil permitió que germinara el estudio de las cuestiones estratégicas como ciencia.

De todos los pensadores estratégicos de su tiempo, Jomini fue el más influyente. Este, al igual que la mayoría, puso el énfasis en encontrar las 
claves del arte de las operaciones militares, lo que se conoce como el álgebra de la acción. Clausewitz escogió u enfoque mucho más filosófico, pero tardó demasiado en darse a conocer. Se dio además la circunstancia de que acabadas las guerras napoleónicas se produjo un prolongado periodo de paz, al tiempo que la Revolución Industrial transformaba profundamente la actividad humana en su conjunto, incluido el fenómeno bélico.

La sistematización del pensamiento militar facilitó que los principios de la era napoleónica arraigaran en la profesión de las armas. Cuando, a mediados del siglo XIX, los ejércitos tuvieron serias dificultades para adaptarse a las nuevas circunstancias, surgió un nuevo genio, Moltke, quien reflexionó serenamente sobre el proceso que se estaba produciendo y fue capaz de dar una respuesta organizativa y operativa a la guerra de la era industrial.

A pesar de que el nuevo entorno operativo tendía a reforzar la defensiva y al estancamiento operativo, la superioridad organizativa e intelectual de Moltke permitió obtener la victoria por medio de campañas rápidas culminadas por un gran batalla decisiva, según el modelo napoleónico. Por entonces, se descubrió también a Clausewitz que fue citado por el general prusiano como una de sus lecturas de cabecera.

Se establecieron una serie de dogmas militares que dinamizaron y falsearon al mismo tiempo la realidad del fenómeno bélico. El proceso de movilización de los ejércitos se convirtió en la esencia del planeamiento militar. Se pensaba que el que movilizara primero contaría con una enorme ventaja para disputar la batalla decisiva que había de producirse en unas pocas semanas. Todo dependía de unos planes minuciosos que se imponían por encima de importantes consideraciones de toda índole. Había que ganar la batalla a cualquier precio, el resultado de la guerra dependía de ello. La mentalidad ofensiva, que había quedado bendecida tanto por Napoleón como por Moltke, aunque este último nunca fuera de aquella opinión, condicionaba los enfoques estratégicos.

Ignorando el abismo al que Europa se estaba acercando, las potencias de entonces se dejaron arrastrar por el interés geopolítico y la pasión del nacionalismo. La Primera Guerra Mundial puso todo en su sitio y dio a conocer la espantosa dimensión que la guerra estaba adquiriendo. Es verdaderamente paradójico que un siglo después de haber nacido la estrategia como ciencia, el arte militar llegara a tocar fondo de una manera tan dolorosa y autodestructiva.

Nuestro tiempo se enfrenta de nuevo a una revolución estratégica, esta vez como consecuencia del profundo reordenamiento del orden internacional. No deberíamos olvidar las grandes lecciones que las guerras enseñan al precio de enorme destrucción y sufrimiento. 


\section{Referencias bibliográficas:}

Griess, Thomas E. The Great War, the Wets Point Military History Series, New Jersey, Avery Publishing Group, 1986.

Griess, Thomas E. The Wars of Napoleon, the Wets Point Military History Series, New Jersey, Avery Publishing Group, 1984. Martínez Teixidó, Antonio, Enciclopedia del Arte Militar, Barcelona, Editorial Planeta, 2001.

Mead Earle, Edward, Makers of Modern Strategy, Princeton University Press, 1971.

Paret, Peter, Creadores de la estrategia moderna: desde Maquiavelo a la era nuclear, Madrid, Ministerio de Defensa, 1991. 